\title{
SPIRITUALISME RATU KALINYAMAT: Kontroversi Tapa Wuda Sinjang Rambut Kanjeng Ratu di Jepara Jawa Tengah
}

\author{
Nur Said \\ STAIN Kudus \\ email: nursaid@ymail.com
}

\begin{abstract}
In Javanese tradition, patriarchal culture is hold strongly though it cannot be generalized as a necessity. The emergence of Queen Kalinyamat as the representation of Javanese woman apparently indicates a contrary to the mainstream Javanese tradition. This article is a semiotical analysis on the spiritualism of Queen Kalinyamat who lived in the 16th century and protested against injustice in that time. She sent the military forces to Malacca to repel the Portuguese so that she was known as a wealthy and very powerful woman. Meanwhile, when her husband and brother were killed by Arya Penangsang, she also demanded justice by living as a naked ascetic (tapa wuda sinjang rambut) which resulted in multiple spiritual interpretations for grass root society. This is mostly interpreted as the spirit of sex drive, but the sufis interpreted it as meaningful metaphor to leave all sorts of worldly power material and position, then it is symbolized by the Arabic letter of Alif. Naked in this case is as a symbol of selfemptying and then filled with repentance, love and taqorrub to God. Queen Kalinyamat's spiritualism counters the Javanese tradition toward different perspective reflecting eco-feminism trend in post-colonial era.
\end{abstract}

Dalam tradisi Jawa, budaya patriarki masih sangat kuat meskipun tidak bisa digeneralisasi sebagai suatu keniscayaan. Munculnya Ratu Kalinyamat sebagai representasi perempuan di Jawa, ternyata menunjukkan kondisi bertentangan dengan tradisi Jawa secara umum. Artikel ini melalui analisis semiotik membahas spiritualisme Ratu Kalinyamat di Jepara, Jawa Tengah yang hidup di abad ke16 dan berani protes terhadap ketidakadilan pada waktu itu. Dia mengirimkan armada pasukan militer ke Malaka untuk mengusir penjajah Portugis hingga dikenal sebagai wanita kaya dan sangat kuat. Sementara itu, ketika suami dan 
kakaknya dibunuh oleh Arya Penangsang, dia juga menuntut keadilan dengan bertapa telanjang (tapa wuda sinjang rambut) yang telah melahirkan multi-makna spiritual di masyarakat akar rumput. Meskipun sebagian memaknainya sebagai semangat gairah seksual, kalangan sufistik memandangnya sebagai perilaku simbolik yang bermakna meninggalkan segala macam kekuasaan duniawi baik material dan jabatan sehingga dilambangkan dengan huruf Arab Alif. Telanjang dalam hal ini sebagai simbol pengosongan diri dan kemudian diisi dengan pertobatan, kasih dan taqorrub kepada Allah. Spiritualisme Ratu Kalinyamat menentang tradisi Jawa yang cenderung patriarki menuju perspektif yang berbeda yang mencerminkan trend ecofeminisme di era poskolonial.

Key words: Ratu Kalinyamat, spiritualism, sex, sufism, tapa unda sinjang rambut

\section{Pendahuluan}

Dalam tradisi Jawa, terdapat konstruksi bahwa perempuan merupakan "konco wingking" (teman belakang) atau sebagai kelas kedua. Dalam hal pembagian peran, perempuan cenderung ditempatkan di ruang domestik (urusan dalam rumah tangga) sebagaimana dalam ungkapan sumur, kasur dan dapur. Bahkan RA Kartini yang dikenal sebagai pejuang emansipasi perempuan Indonesia menjadi korban tradisionalisme Jawa yang cenderung patriarkhal yang direproduksi oleh generasi tua:

“...kisah Kartini jadi penting bukan karena heroismenya, melainkan karena kegagalannya. Dialah perempuan yang mencoba menunggang gelombang - khas generasi muda - tapi terjebak dalam paluan ke-tua-an. Dalam masyaraktnya, panutan adalah ingatan. Yang membentuk adalah pengulangan khazanah yang disusun oleh generasi tua. Tradisi hampir menentukan segalanya..." (Mohamad, 2006: 25-31).

Kartini dalam konteks kehidupannya bisa dibilang gagal dalam memperjuangkan idealisme yang sejak awal membenci kehidupan poligami ayahnya sendiri yang memperlakukan istri-istrinya secara tidak adil (Arbaningsih, 2005: 25). Namun demikian, dalam setiap periode tertentu, selalu ada peristiwa yang menunjukkan justru perempuanlah yang menjadi aktor sejarah hingga membawa zaman keemasan. Sebut saja Ratu Kalinyamat yang hidup di pesisir utara Jawa. Ratu Kalinyamat adalah salah satu figur perempuan yang dikenal sebagai pejuang heroik yang dijuluki "De Krange Dame" (Perempuan yang gagah berani) oleh orang Portugis (Gustami, 2000: 100).

Ratu Kalinyamat mampu mendobrak kemapanan kiprah ruang publik yang biasanya didominasi oleh laki-laki bahkan dia berhasil menjadi seorang 
Ratu Jepara yang sangat berkuasa hingga Diego De Conto, seorang penulis Portugis menjuluki Ratu Kalinyamat sebagai "Rainha de Jepara senhora Poderosa e rice" (Ratu Jepara, seorang perempuan yang sangat berkuasa) (Said, dkk., 2005; 2). Namun, Ratu Kalinyamat tetaplah manusia biasa yang pernah juga mengalami keterpurukan jiwa terutama ketika suami yang dicintainya, Sultan Hadiri, terbunuh menyusul kematian saudara laki-lakinya, Sunan Prawata di tangan Arya Penangsang hanya karena faktor kepentingan politik. Menghadapi hal ini Ratu Kalinyamat melancarkan protes terhadap ketidakadilan penguasa yang direpresentasikan oleh Arya Penangsang. Arya Penangsang bagi Kalinyamat adalah simbol keserakahan dunia (Said, dkk., 2005: 2).

Sebagai wujud protes terhadap keserakahan Arya Penangsang, Ratu Kalinyamat bertekad "bertapa telanjang" yang oleh masyarakat sekitar populer dengan istilah "tapa wudo sinjang rambut sinjang". Memang belum ditemukan kata sepakat mengenai makna tentang cara pertapaan Ratu Kalinyamat yang "mertapa awuwudha wonten ing redi Dana Raja. Kang minangka tapih ramanipun kaore" itu sebagai sungguh-sungguh bertapa telanjang di gunung Danaraja atau sekedar kiasan.

Tulisan ini mengurai posisi Ratu Kalinyamat di tengah jejak Kesultanan Demak hingga kekuasaan Jepara; mulai dari akar konflik pesisir yang melibatkan Ratu Kalinyamat dan Aryo Penangsang hingga kontroversi tafsir tentang "tapa wudo sinjang rambut" Kanjeng Ratu yang populer hingga sekarang. Terdapat tiga persoalan yang akan dijawab dalam tulisan ini, yaitu: (1) Siapa sosok Ratu Kalinyamat dan sejauh mana ia terlibat dalam kekuasaan di Jepara baik mulai dari akar konflik hingga keemasan Jepara? (2) Bagaimana kiprah Ratu Kalinyamat hingga ia dikenal sebagai pemimpin yang sangat berkuasa dan heroismenya yang tinggi?; (3) Bagaimana kontroversi spiritualisme Ratu Kalinyamat terkait "tapa wuda sinjang rambut" antara kalangan elit penguasa dan masyarakat akar rumput?

\section{Kerangka Teori}

Dalam sejarah umat manusia, kehadiran agama tak lepas dari jawaban atas usaha manusia untuk menemukan makna dan nilai dalam realitas kehidupannya. Manusia dalam dirinya selalu ada keinginan untuk memburu makna spiritual dalam diri dan lingkungannya, maka manusia disebut sebagai makhluk spiritual (spiritual animal) atau dikenal juga sebagai homo religious (Armstrong, 1993: 14). 
Maka tak berlebihan juga kalau ada yang mengatakan bahwa umat beragama dalam realitas sosialnya sesungguhnya juga mengenal adanya dimensi spiritual yang sakral (the reality of the Sacred) (Eliade, 1996: 158) atau disebut bahwa society as Sacred (Durkheim, 1996: 88), dalam realitas sosial juga sarat dengan fenomena yang sakral.

Perilaku Ratu Kalinyamat, sebagai sosok penguasa Jepara pada saat itu, ketika sedang dirundung duka, lalu melakukan "tapa wuda sinjang rambut" yang kontroversial itu tentu sarat dengan makna spiritual. Apalagi Ratu Kalinyamat dalam struktur sosial budaya masyarakat pesisir pada saat itu sebagai figur publik yang tentu akan menjadi referensi perilaku bagi masyarakat di sekitarnya. Masyarakat Indonesia dipengaruhi oleh tiga fenomena; modernitas, agama dan budaya nenek moyang. Tidak ada golongan modern, golongan agama atau golongan budaya yang murni. Karena itu, spiritualisme selalu hadir dalam ruang kehidupan manusia selama manusia tumbuh rasa ingin tahu dalam menemukan makna dalam realitas kehidupannya (Risakotta, 2002: 123).

Maka Ratu Kalinyamat sebagai bagian dari nenek moyang masyarakat pesisir, ternyata perilaku tapa wuda sinjang rambut -nya telah melahirkan beragam tafsir spiritual yang bergulat dalam konstestasi tanda budaya yang begitu dinamik. Semua itu tak lepas dari kepentingan pencitraan sebagai sistem tanda (sign) yang di dalamnya menyimpan penanda (signifier) sebagai aspek material dan petanda (signified) sebagai aspek moral yang "ideologis" (Barthes, 1967: 41-48; Barthes, 1983: 115). Dalam pergulatan seperti itulah spiritualisme Ratu Kalinyamat akan didiskusikan dalam tulisan ini

\section{Jati Diri Ratu Kalinyamat}

Berdasarkan sumber yang tersebar di Jepara, silsilah Ratu Kalinyamat menunjukkan bahwa Ratu Kalinyamat termasuk masih keluarga besar dari kerajaan Demak. Menurut "Babad Tanah Jawi" Ratu Kalinyamat disamping memiliki "darah biru" dalam kerajaan Demak, juga memiliki akar keturunan etnis Tionghoa. Hal ini bisa dirunut dari perkawinan Raden Patah dengan Putri Cina yang memiliki enam putra. Yang terbesar adalah seorang putri Raden Mas yang kemudian menikah dengan Pangeran Cirebon. Adik-adiknya berjumlah 5 (lima) orang, semuanya laki-laki yakni: (1) Pangeran Sabrang Lor yang kelak menjadi Sultan Demak II atau dikenal dengan Raden Surya yang identik dengan Pati Unus (Penguasa Jepara), (2) Pangeran Sedo Lepen (Raden Mas Alit), (3) Pangeran Trenggana, (4) Raden Kanduruwan, (5) Raden Pamekas (Dokumen "Lembaran Daerah Kabupaten Daerah Tingkat II Jepara 
Nomor 2 Tahun 1989 Seri D No. 1" dalam Masya, 1991; 4).

Setelah Raden Patah yang bergelar Sultan Demak I meninggal dunia, beliau digantikan oleh putranya Pangeran Sabrang Lor (Pate Rodem Senior) yang kemudian bergelar Sultan Demak II. Dalam masa pemerintahan antara 2-3 tahun (1518-1521) Pangeran Sabrang Lor meninggal yang kemudian digantikan oleh Sultan Trenggana (Pate Rodem Yunior) yang bergelar Sultan Demak III. Sebenarnya yang berhak menggantikan adalah Pangeran Sedo Lepen, karena dialah sebagai saudara tertuanya. Namun karena Pangeran Sedo Lepen juga telah meninggal karena dibunuh oleh Pangeran Prawata putra Sultan Trenggana. Inilah yang kemudian hari berdampak pada dendamnya Arya Penangsang terhadap anak keturunan Sultan Trenggana (Dokumen "Lembaran Daerah Kabupaten Daerah Tingkat II Jepara Nomor 2 Tahun 1989 Seri D No. 1”).

Sementara Sultan Trenggana juga memiliki 6 (enam) keturunan; (1) Pangeran Mukmin (Sunan Prawata), (2) Putri I (Putri Kenya), (3) Putri II (Retna Kencana), (4) Putri III (Retna Mirah), (5) Putri IV, (6) Putri V. Retna Kencana dalam silsilah tersebut merupakan Ratu Kalinyamat yang dikenal sekarang (Hayati, dkk., 1991: 26-43; Said, dkk., 2005: 43-46).

Versi inilah yang lebih kuat dan tersosialisasi dalam masyarakat Jepara hingga ke arus bawah. Bahkan untuk menunjukkan kebesaran Ratu Kalinyamat sebagai "perempuan suci" dari keluarga raja silsilah Ratu Kalinyamat secara jelas dan cukup menonjol dipasang di depan Makam Kramat Ratu Kalinyamat Mantingan Jepara.

Dalam silsilah tersebut digambarkan bahwa bahwa Ratu Kalinyamat memiliki keturunan langsung dengan pendiri kerajaan Demak, Raden Patah melalui anaknya Sultan Trenggana. Sebagaimana dikenal dalam sejarah bahwa Kerajaan Demak adalah kerajaan Islam yang berpengaruh menyebarkan Islam di Pulau Jawa. Bahkan peninggalannya yang berupa monumen sejarah Masjid Agung Demak sebagai simbul keislaman menjadi daya tarik para peziarah dari berbagai kota dan bahkan manca negara.

Hal demikian menjadikan citra Ratu Kalinyamat sebagai sosok perempuan yang sangat dekat dengan Islam baik secara politis, sosial maupun budaya. Citra keislaman ini masih diperkuat dengan adanya peninggalan Masjid Mantingan yang sarat dengan ornamen seni ukir yang bernilai tinggi. Masjid ini sekarang dikenal dengan Masjid Astana Sultan Hadiri Mantingan Jepara.

Selain makam Ratu Kalinyamat di Kompleks Makam Masjid Astana Sultan Hadiri Mantingan Jepara terdapat sejumlah nama-nama besar antara 
lain Sultan Hadiri yang tak lain suaminya sendiri, bersebelahan dengan posisi makam Ratu Kalinyamat dan R. Abdul Jalil yang dikenal dengan Sunan Jepara yang oleh kalangan pengunjung Sufi dikenal dengan Syaikh Siti Djenar. Selain itu juga terdapat makam Raden Ayu Prodobinabar (anak Sunan Kudus), istri kedua Sultan Hadiri; Makam Patih Cie Wie Gwan dan istri yang dikenal dengan peletak seni ukir di Jepara; makam Senopati Abdurrahman dan istri; serta ketiga anaknya. Namun figur Ratu Kalinyamat tetap mendapat "tempat istimewa" di mata para peziarah di kompleks makam tersebut.

Kebesaran nama Ratu Kalinyamat dalam masyarakat Jepara dan para peziarah telah meneggelamkan nama sebenarnya. Dalam beberapa tulisan yang merujuk pada "Babad Tanah Jawa", nama aslinya adalah Retna Kencana. Sedangkan yang merujuk pada "Hikayat Hasanuddin" dari Banten Ratu Kalinyamat memiliki julukan Ratu Arya Jepara. Sementara keterangan dari Juru Kunci Makam Ratu Kalinyamat dikenal juga dengan Raden Ayu Wuryani (Said, dkk., 2005: 49; Masya, 1991: 13-15).

\section{Heroisme Ratu Kalinyamat}

Salah satu kebesaran Ratu Kalinyamat yang mempopulerkan citranya sebagai pemimpin kuat dan kaya raya adalah adalah prestasi kepemimpinannya di Jepara pada abad XVI. Hal ini selalu dikampanyekan oleh pihak-pihak berkepentingan terutama oleh Pemda Dati II Jepara untuk mengambil semangat kebesaran dan patriotismenya bagi konteks sekarang. Berbagai dokumen dan buku-buku yang diterbitkan oleh Pemda Jepara selalu memunculkan dan menonjolkan prestasi kekuasaan Ratu Kalinyamat secara sistematis. Upayaupayanya bisa melalui momen upacara resmi Hari Jadi Kota Jepara, media massa atau Majalah Lokal Gelora Kartini, ritual "Buka Luwur" di kompleks pemakaman Ratu Kalinyamat dan lainnya.

Meskipun demikian, cerita tentang kemelut di Demak yang melibatkan Ratu Kalinyamat juga tak bisa dihindari. Kemelut tersebut terjadi sejak tewasnya Sultan Trenggana sebagai Sultan Demak III dalam ekspedisi militer pada tahun 1546 di Panarukan, Jawa Timur. Sebagai gantinya adalah puteranya yaitu Sunan Prawata sebagai Sultan Demak IV. Namun pemerintahannya tidak berlangsung lama karena Pangeran Prawata menjadi korban pembunuhan Adipati Jipang Panolan, Arya Penangsang.

Perbuatan Arya Penangsang merupakan wujud dendam atas terbunuhnya Pangeran Sedo Lepen, Raden Mas Alit, oleh utusan Pangeran Prawata. Hal ini juga sekaligus memenuhi ambisinya untuk merebut tahta Kerajaan Demak. 
Sasaran pembunuhan berikutnya adalah Menantu Sultan Trenggana, yaitu Pangeran Hadiwijaya (Jaka Tingkir atau Mas Karebet) dari Pajang, meskipun niat jahat ini akhirnya gagal. Untuk memperkuat ambisinya Arya Penangsang juga menghabisi Pangeran Hadiri, suami Ratu Kalinyamat setelah beliau menghadap Sunan Kudus bersama istrinya.

Peristiwa terbunuhnya saudara dan suami inilah yang menyebabkan Ratu Kalinyamat melakukan "laku tapa" di bukit Danaraja dekat daerah Keling, sekarang dikenal dengan Sonder Tulakan Keling. Laku tapanya tersebut tidak akan diakhiri sebelum Adipati Arya Penangsang terbunuh. Cerita tentang laku tapa Ratu Kalinyamat inilah populer di masyarakat Jepara dengan "tapa wuda sinjang rambut" yang melahirkan spiritalisme tafsir sosial dari berbagai komunitas masyarakat dari elite politis, elite agama (thariqat) maupun dalam masyarakat awam yang akan dibicarakan secara khusus pada bagian lain.

Upaya pembunuhan yang dilakukan oleh Arya Penangsang ternyata mendapat "dukungan" dari Sunan Kudus, kendatipun perselisihan ini akhirnya dapat dimenangkan oleh pihak sekutu Ratu Kalinyamat dan Pangeran Hadiwijaya dari Pajang dengan terbunuhnya Arya Penangsang oleh putra angkat Pangeran Hadiwijaya yaitu Danang Sutawijaya. Danang Sutawijaya inilah yang akhirnya menjadi cikal bakal berdirinya Kerajaan Mataram Islam. Peristiwa terbunuhnya Aryo Penangsang terjadi pada tahun 1549 dan kesempatan ini digunakan oleh sekutu Ratu Kalinyamat untuk menobatkan Ratu Kalinyamat sebagai penguasa Jepara. Momen penobatan ini ditandai dengan candra sengkala “Trus Karya Tataning Bumi” pada tanggal 10 April 1549.

Pada masa kekuasaan Ratu Kalinyamat, Jepara dikenal sebagai bandar niaga yang ramai dan merupakan daerah makmur, gemah ripah loh jinawi. Ratu Kalinyamat dikenal memiliki jiwa patriotisme dan anti terhadap segala bentuk penjajahan. Hal ini dibuktikan dengan pengiriman armada perangnya ke Malaka untuk menggempur Portugis tahun 1551 dan 1574.

Atas prestasi inilah buku-buku resmi yang diterbitkan oleh Pemda memperkuatnya dengan berbagai data pendukung termasuk berbagai pernyataan orang-orang Portugis yang menyiratkan ketakjubannya. Misalnya tentang terkesannya orang Portugis atas keberanian Ratu Kalinyamat sehingga mereka menyebut sang ratu sebagai "De Krange Dame" (wanita yang gagah berani). Demikian juga kekaguman De Couto, seorang penulis bangsa Portugis dalam bukunya "Da Asia" juga dimunculkan dengan menyebut Ratu Kalinyamat sebagai "Rainha de Jepara senhora Poderosa e rice" (Ratu Jepara, seorang perempuan yang kaya dan mempunyai kekuasaan besar). 
Hal ini bisa dipahami karena armada perang yang dikirim oleh Ratu Kalinyamat ke Malaka melibatkan hampir 40 perahu dengan prajurit sekitar 5.000 orang, meskipun mengalami kegagalan. Pada penyerangan lewat darat yang bertujuan menggempur benteng pertahanan portugis, serangan pasukan Kalinyamat juga masih belum berhasil mematahkan pasukan Portugis. Yang lebih tragis pimpinan prajurit Kalinyamat juga terbunuh sehingga "espada e hum cris guarnacido de ouro" (pedang penikam dan keris dihiasi emas) jatuh ke tangan Portugis. Dengan kenyataan ini akhirnya para prajurit kembali ke perahu dan melanjutkan peperangan di laut. Pada peristiwa ini, hampir 2000 prajurit Kalinyamat gugur dalam pertempuran yang cukup heroik ini. Yang lebih tragis pimpinan prajurit Kalinyamat terbunuh sehingga "espada e hum cris guarnacido de ouro" (pedang penikam dan keris dihiasi emas) jatuh ke tangan Portugis. Dengan kenyataan ini akhirnya para prajurit kembali ke perahu dan melanjutkan peperangan di laut. Pada peristiwa ini, hampir 2000 prajurit Kalinyamat gugur dalam pertempuran yang cukup heroik ini (Hayati, 1991: 50-53).

Kendati demikian, semangat patriotisme Ratu Kalinyamat tidak pernah luntur dan tetap membara mengusir penjajah. Maka diceritakan, 24 tahun kemudian Oktober 1574, Ratu Kalinyamat mengirimkan kembali armada militer ke Malaka yang jauh lebih besar yakni terdiri dari 300 kapal dengan 15.000 prajurit. Armada militer kedua dipimpin oleh "Regedor Principal de Seu Reyno" (pengusaha terpenting dalam kerajaan) yang disebut "Quilimo" yang diduga merupakan julukan dari "Kyai Demak". Peperangan kedua ini -dengan mengutip sejarawan De Couto- berakhir dengan perundingan dan negosiasi politik. Namun tuntutan pihak Portugis dirasa terlalu berat sehingga tidak menemukan kesepakatan. Akibatnya pihak Portugis merampas enam kapal yang penuh dengan bahan-bahan makanan, pasukan Kalinyamat akhirnya memutuskan mundur kembali ke Jepara.

Sejarah dan kisah Ratu Kalinyamat telah dikomunikasikan secara sistemik oleh masyarakat Jepara terutama oleh Pemda setempat. Dalam hal ini masyarakat Jepara telah berhasil membuat sejarah yang mampu memukau publik melalui strategi komunikasi yang diperankannya. Ratu Kalinyamat dalam sejarah dan kisah yang tertutur di atas merupakan bagian dari cara berkomunikasi masyarakat dalam menemukan dan menangkap kesejatian diri Ratu Kalinyamat.

Masyarakat menggunakan tanda-tanda dengan memilih, menggabungkan dan menungkapkan tanda-tanda tersebut untuk menghasilkan makna tertentu 
(signifying practice) dan mengungkapkan diri (communication) atas apa yang terjadi pada diri Ratu Kalinyamat. Ratu Kalinyamat yang semula "ditentukan” sebagai peristiwa historis menjadi ditentukan dalam sistem mitis. Peristiwa historis seperti ini tidak lagi sekedar dipahami sebagai historis melainkan mitis. Pada titik ini telah terjadi suatu proses dehistorisasi yakni menunjuk kekuatan mitis untuk mencabut status historis konsep dan bentuk tentang Ratu Kalinyamat. Pada saat yang sama proses naturalisasi juga berlangsung lantaran naturalisasi merupakan mesin mitis (semiotik) untuk menghasilkan esensi-esensi yang tak terbatas (Barthes, 1983: 142). Sehingga terjadi tarik menarik dan pertarungan bebas yang berlangsung secara dialektis antara sistem tanda yang ada dengan kebebasan orang untuk memilih dan memakainya sesuai kebutuhan pribadi atau kelompok dari komunitas tertentu yang jelas di dalamnya mengandaikan adanya efek (naturalizing effect). "Natural" adalah pengalaman utama dalam mitos yang di dalamnya mencerminkan ideologi.

\section{Spiritualisme Tapa Wuda Sinjang Rambut}

Sebagaimana disinggung sebelumnya, diantara lelaku Ratu Kalinyamat yang paling kontroversial dan melahirkan dinamika "makna spiritual" dalam masyarakat Jepara adalah tapa bratanya yang dikenal dengan 'tapa wuda sinjang rambut”. Kenekatan Ratu Kalinyamat yang memutuskan "bertapa telanjang” terekam dalam cerita rakyat melalui tembang Pangkur berikut ini;

"Nimas Ratu Kalinyamat tilar pura, mratapa aneng wukir, tapa wuda sinjang rambut, aneng wukir Donorojo, aprasapa nora tapih-tapihan ingsun, yen tan antuk adiling Hyang, patine sedulur mami" (Masya, 1991: 24; Prasetyo, tt: 11)

Tembang itu menggambarkan sumpah Ratu Kalinyamat, setelah Sunan Prawata saudaranya dan Sultan Hadiri suaminya, dibunuh Arya Penangsang dari setelah lengsernya Sultan Trenggana. Perempuan perkasa ini kemudian "tilar wisma", meninggalkan rumah, untuk bertapa di "wukir", Gunung Danaraja. Sebelum memperoleh keadilan Tuhan, yaitu ditunaikannya "hukum bunuh balas bunuh" atas Arya Penangsang, ia akan tetap "tapa wuda sinjang rambut" melepas pakaian dan menutup tubuhnya hanya dengan rambut 
yang terurai.

Mencermati isi teks yang terkandung dalam tembang Pangkur di atas tampaknya merupakan bagian dari karya sastra karena di dalamnya ditemukan makna tekstual yaitu makna yang dihasilkan dari interaksi bagian-bagian teks satu dengan lainnya dan menempatkan sejauh mungkin makna referensial, sehingga dimungkinkan adanya konotasi dan diaktifkannya ambivalensi untuk menghidupkan watak simbolik sastra (Kleden, 2004: 7-8).

Tembang Pangkur tersebut menggambarkan pencarian keadilan Ratu Kalinyamat atas kedhaliman yang menimpanya lantaran saudaranya, Sunan Prawata dan suami yang dicintainya, Sultan Hadiri meninggal akibat keserakahan Arya Penangsang yang haus kekuasaan. Ungkapan dalam tembang Pangkur "tapa wuda sinjang rambut" memiliki beragama makna yang denotatif, konotatif hingga yang ambivalensi.

Tembang Pangkur dalam kedudukannya sebagai sastra setidaknya akan memiliki 3 (tiga) fungsi; (1) Memberikan pengetahuan tentang kenyataan disebut sebagai fungsi mathesis atau merupakan wilayah baru untuk diketahui (the possible area of knowledge), (2) Menghadirkan sesuatu yang tidak mungkin dihadirkan disebut fungsi memesis, (3) Menghidupkan tanda (to act sign) atau disebut fungsi semiosis (Sunardi, 1992: 242-243).

Dengan demikian melalui tembang Pangkur di atas pembaca akan mampu: (1) Menangkap kenyataan tapa brata Ratu Kalinyamat sebagai wilayah baru yang bisa diketahui meski dengan interpretasi yang heterogen, (2) Menghadirkan dan mengaktualkan kembali semangat dan patriotisme Ratu Kalinyamat kendatipun kehadirannya tidak akan sama persis dalam konteks Ratu Kalinyamat hadir dalam ruang sejarah atau cerita, (3) Menempatkan fenomena tapa brata sebagai fenomena tanda yang tidak terpisahkan dari adanya penanda dan petanda.

Belum diketahui siapa sebenarnya pengarang (author) asli dari teks tembang Pangkur tersebut. Tidak munculnya pengarang dalam tembang pangkur tersebut bukanlah persoalan mendasar. Hal ini justru akan malahirkan “pembaca kritis" yang menuntut kematian author atau kematian otoritas makna teks yang dianggap sebagai sumber makna akhir. Kalaupun ada pengarang sesungguhnya suara pengarang hilang ("mati") bersamaan munculnya teks (Barthes, 1975: 27).

Dengan pertimbangan inilah tapa brata Ratu Kalinyamat yang dikenal dengan tapa wuda sinjang rambut bukan lagi milik pengarang tetapi sudah miliki pembaca. Maka yang terpenting adalah tidak bersibuk diri melacak 
makna yang mungkin disembunyikan pengarang tetapi bagaimana pembaca memproduksi makna. Maka untuk kepentinga ini penulis akan memetakan pluralitas makna itu berdasarkan pendekatan dan perspektif pembaca secara lebih spesifik:

\section{Tafsir Elit Penguasa}

Menurut tafsir penguasa, dalam hal ini yang muncul dari pihak pemerintah seperti melalui berbagai penerbitan buku, lembaran daerah, majalah bulanan, pidato resmi pemerintahan ataupun bentuk lainnya menilai bahwa fragmen tapa wudanya Ratu Kalinyamat tidak tepat kalau dimaknai secara literal. Pihak pemerintah cenderung memaknai "tapa wuda" memiliki pengertian meninggalkan segala bentuk urusan keduniaan dan melepaskan kebesaran mahkota sebagai Ratu lalu menyendiri ke gunung Danaraja untuk menemukan keheningan memohon petunjuk kepada Yang Maha Kuasa agar mendapatkan keadilan. Jadi "telanjang" lebih dimaknai sebagai kiasan (konotatif) yang menyiratkan suatu bentuk pelepasan segala bentuk urusan keduniaan termasuk urusan kerajaan (Prasetyo, tt: 14; Lembaran Daerah Kabupaten Daerah Tingkat II Jepara Nomor 2 Tahun 1989 Seri D No. 1; 38 39) sikap Ratu Kalinyamat itu sebagai bentuk kesetiaan istri terhadap suami yang dicintainya (Hisom Prasetyo, tt: 14).

Kata "wuda" tidak dimaknai secara lugas yang berarti "telanjang" akan tetapi sebagai ungkapan kiasan yang harus ditafsirkan. Hal ini didasarkan atas pertimbangan bahwa sudah menjadi kebiasaan para pengarang naskah-naskah sejarah tradisional di Jawa menggunakan lambang dan kiasan. Kebiasaankebiasaan ini terkait dengan sifat masyarakat Jawa yang senang sekali dengan olah rasa dengan menggunakan rasa pangrasa (Lembaran Daerah Kabupaten Daerah Tingkat II Jepara Nomor 2 Tahun 1989 Seri D No. 1; 38; Said, dkk., 2005: 63-64). Hal ini diperkuat dengan penilaian Kyai Hadisiswaya sebagaimana dikutip Tim Penyusun naskah sejarah Sultan Hadiri dan Ratu Kalinyamat dalam rangka menyambut khoul Sultan Hadiri Mantingan yang menyatakan bahwa:

“...Bagi orang tua zaman kuno, sekiranya diceritai, diajar barang-barang yang jelas, terang-terangan, hal itu tidaklah senang. Kesenangannya mengenai perasaan, barang-barang yang bisa memecahkan pikirannya...oleh karenanya semua cerita orang tua dan ajarannya yang termuat dalam peninggalannya dalam buku-buku, kitab kitab, itu semua berisi kiasan dan perlambang" (Masya, 1991: 25).

Pola penafsiran seperti itulah yang dikembangkan dan disosialisasikan 
oleh pemerintah sebagai salah satu bentuk koreksi terhadap pemahaman dalam masyarakat melalui cerita rakyat yang cenderung dimaknai lugas sehingga berdampak pada kesadaran etis yang "kontraproduktif."

\section{Tafsir Masyarakat Bawah}

Ada beberapa versi masyarakat bawah dalam memaknai "tapa wuda sinjang rambut". Dalam hal ini proses pencarian maknanya tidak lagi terkonstitusi oleh otoritas tertentu tetapi muncul secara bebas oleh masyarakat itu sendiri. Untuk memetakan pola pemaknaan ini penulis mengelompokkan dalam dua perspektif:

(1) Perspektif Cerita Rakyat

Fenomena tapa wuda sinjang rambut dalam masyarakat Jepara sudah tidak asing lagi atau setidaknya Ratu Kalinyamat telah dikenal oleh masyarakat sebagai sosok perempuan yang memiliki kelebihan baik secara fisik maupun mental. Secara fisik Ratu Kalinyamat mencerminkan perempuan yang berparas cantik. Rambutnya yang terurai panjang (sinjang rambut) menambah citra Ratu Kalinyamat sebagai sosok perempuan idola. Secara mental Ratu Kalinyamat dikenal sebagai pribadi tangguh tidak begitu saja menerima bentuk penindasan yang dialami seperti yang menimpa dirinya akibat ulah Arya Penangsang yang telah membunuh saudara dan suaminya.

Berangkat dari rasa tertekan dan nelangsa serta kesedihan mendalam yang dirasakan, Ratu Kalinyamat bersumpah menjalankan tirakat "tapa wuda" di Gunung Danarasa. Bagi masyarakat awam yang di pedalaman terutama yang dekat dengan komplek pertapaan Ratu Kalinyamat cenderung meknai "tapa wuda" secara lugas sebagai telanjang bulat hanya berbaju rambutnya yang panjang terurai. Kesan ini menjadikan Ratu Kalinyamat dikesankan kurang menjaga keperawiran (harga diri) dan moralitas perempuan. Bahkan sampai tingkat tertentu Ratu Kalinyamat dikesankan sebagai "pengumbar seks" meski terkadang untuk tujuan yang baik. Hal ini didukung dengan berbagai cerita yang menuturkan bahwa dalam kejayaan Ratu Kalinyamat sering menerima para tamu dari negeri asing. Untuk menguji kejujuran para tamu apakah benar-benar memiliki tujuan yang baik atau sebaliknya, Ratu Kalinyamat menerima tamu tersebut di istana untuk istirahat di kamar pribadi Ratu Kalinyamat. Kalau ternyata tamu tersebut tergoda dengan niat busuk yang berujung pada perbuatan yang tidak diinginkan, maka Ratu Kalinyamat tidak segan-segan membunuhnya (Said, dkk., 2005: 64; Lembaran Daerah Kabupaten Daerah Tingkat II Jepara Nomor 2 Tahun 1989 Seri D No. 1; 
30-31; Masya, 1991: 5-12).

Namun kesan bahwa Ratu Kalinyamat sebagai "pengumbar seks" menurut Juru Kunci Sonder, Pak Parni itu tak lepas dari isu negatif yang disebarkan oleh Arya Penangsang agar citra kebesaran yang dimiliki oleh Ratu Kalinyamat jatuh. Apalagi sejak awal Ratu Kalinyamat memang "rival politik" keluarga Arya penansang menjelang runtuhnya kerajaan Demak. Kesan Ratu Kalinyamat sebagai "pengumbar nafsu" menurut sebagian masyarakat juga diyakini tidak lepas dari propaganda penjajah Belanda yang ingin merusak citra figur lokal yang diidolakan masyarakat. Sehingga unsur politis dalam konteks ini juga sangat menonjol yang kesannya ingin menempatkan Belanda sebagai kelas elite sosial dan sekaligus "penjaga moral" yang harus diteladani sementara figur seperti Ratu Kalinyamat dipinggirkan dan dinafikan karena karakter dan moralitasnya dianggap bobrok dan hiperseks (Said, dkk., 2005: 74-76).

Kesan negatif terhadap Ratu Kalinyamat sebagai pengumbar seks ini ternyata oleh sebagian masyarakat yang memiliki komoditi seks ingin "mengambil berkah" agar mendapatkan "susuk cairing Ratu Kalinyamat". Tidak bisa dielakkan hal ini menjadi salah satu "magnet" yang menjadikan daya tarik para pengunjung mendatangi kompleks pemakaman atau petilasan Ratu Kalinyamat yang dikenal sebagai perempuan yang cantik, berambut panjang. Dalam pernyataan bahasa lokal diceritakan oleh Parni, Pakuncen Komplek Pertapaan Ratu Kalinyamat di Sonder (Nur Said dkk, 2005: 86):

“... susuk cairing Kanjeng Ratu, nek diagem tambah baguse, tambah pantese, tambah kewese, mulo ceritane Jepara meniko nek diencepi moro, nek diencepi priyayi-priyayi putri Jeporo do ketut kabeh".

(...susuk cairing Kanjeng Ratu, apabila dipakai (oleh seseorang) akan bisa menambah kecantikan, kepantasan, dan daya tarik. Maka ceritanya "Jepara" (memiliki kepanjangan) nek diencepi moro (perempuan Jepara kalau sudah memberi senyum) kepada para lelaki, maka para lelaki tersebut akan tertarik semua).

Daya tarik inilah yang membuat para pemburu susuk masih tetap menonjol terutama pada setiap Malam Jumat Wage khususnya di kompleks pertapaan Ratu Kalinyamat, Sonder, Keling, Jepara. Harapannya adalah agar spirit seks yang ada dalam diri Ratu Kalinyamat meliputi aura bagi para peziarah khususnya para kaum perempuan yang berkepentingan.

(2) Persepektif Muslim Sufi

Di kalangan sebagian masyarakat sufi dari golongan Thariqat 
Naqsyabandiyah, Khalidiyah dan Mujaddidiyah di Jepara menganggap Ratu Kalinyamat sebagai "bojo njero" (istri dalam/istri bayangan). "Bojo njero" biasanya melibatkan perempuan sebagai representasinya untuk mendongkrak spiritualitas para wali atau ahli thariqat yang kebanyakan laki-laki untuk sampai Tuhan. Hal ini sebagaimana Ibnu al Arabi ketika mengalami "extasy spiritual” penjelmaannya seakan memandang perempuan cantik di depan Ka'bah sehingga mendorong syahwat spiritrualitasnya menemuai Tuhan. Inspirasinya terhadap "perempuan cantik" oleh Ibnu al Arabi juga telah membuahkan karya tulis dalam sejumlah kitab yang berorientasi tasawuf. Hal yang sama juga dialami oleh Khalil Gibran yang selalu mempunyai "kekasih bayangan” yang selalu menemaninya dimanapun dan kapanpun ia pergi. Kekasih bayangan tersebut memberaikan inspirasi Gibran bagi lahir banyak karya sastra (Said, dkk., 2005: 79). Hal ini dimaksudkan sebagai wahana (wasilah) untuk mengantarkan para salik menemui Tuhan. Kalinyamat menurut mereka berasal dari bahasa Arab, yaitu kalimat, yang berarti kalimat syahadat. Membaca kalimat syahadat dalam Islam merupakan rukun pertama dari lima rukun Islam. Dengan demikian syahadat merupakan inti dalam Islam. Berdasarkan alasan tersebut istilah "Kalinyamat" di kalangan Sufi merupakan simbul dari inti Islam sehingga ada di antara mereka yang menjadikan Ratu Kalinyamat sebagai "guru spiritual" sebagian masyarakat Sufi di Jepara yang akan membimbingnya menuju Tuhan (Said, dkk., 2005: 79).

Karena itu penafsiran kelompok kaum sufi, sebagaimana diakui $\mathrm{KH}$ Nuruddin Amin memahami "tapa wuda" dalam pengertian "telanjang" sebagai tanda meninggalkan semuanya (segala urusan dunia) dan selanjutnya hanya menuju satu tujuan yaitu menuju Allah SWT. "Tapa wuda” dipahami sebagai pelarian spiritual Ratu Kalinyamat setelah dihadapkan dengan kegelisahan yang bersifat keduniaan yang berujud urusan kerajaan, terbunuhnya saudara dan suami yang dicintainya, keserakahan dan seterusnya (Said dkk, 2005: 79-80). Hal ini kemudian pada tingkat tertentu telah menempatkan Ratu Kalinyamat sebagai "guru spiritual" atau setidaknya kekaguman masyarakat (Sufi) Jepara terhadap Ratu Kalinyamat. Bahkan mereka telah menjadikannya sebagai strategi dakwah dengan memasukkan aliran thariqat dalam perspektif Jawa. Jadi bukan lagi murni Naqsyabandiyah, Khalidiyah dan Mujaddidiyah. Caranya adalah dengan memasukkan unsur-unsur budaya lokal (kepopuleran Ratu Kalinyamat), kemudian dibugkus dengan nilai-nilai Islam melalui ajaran thariqat.

Mendudukkan Ratu Kalinyamat sebagai "guru spiritual” dalam kehidupan 
Sufi di Jepara menjadi fenomena tersendiri yang unik meski masih dalam komunitas yang sangat terbatas. Hal ini hanya bisa dilakukan ditangkap bagi mereka yang mampu memahami dan merenungkan dengan kejernihan hati dan pikiran yang bersih. Apalagi ajaran Sufi Ratu Kalinyamat dalam kebanyakan buku yang ada belum pernah diungkap.

Ratu Kalinyamat sebenarnya telah memberikan filosofi hidup yang dikenal dengan rahasia huruf Alif sebagai ajaran Tauhid tingkat tinggi. Ajaran rahasia huruf Alif yang berorientasi tauhid (pernyataan keesaan Tuhan) juga tercermin secara monumental dalam tulisan bahasa Arab pada gapura pintu masuk kompleks masjid Mantingan dan Makam Kramat Ratu Kalinyamat. Gupura ini menjadi "tugu identitas" yang dibanggakan oleh warga Jepara. Bunyinya adalah "asyhadu an lâ ilâha illâh" (saya bersaksi bahwa tiada Tuhan selain Allah).

Hanya komunitas terbatas dari orang-orang tertentu yang mampu menemukan dan berkesimpulan bahwa Ratu Kalinyamat memiliki ajaran tasawuf tingkat tinggi. Hal ini seperti diuraikan oleh KH. Masrukhan, Juru Kunci kompleks pertapaan Ratu Kalinyamat Sonder bahwa ketika Ratu Kalinyamat menjelang pertapaaannya di Sonder, beliau mencari tempat yang benar-benar hening dan bisa mendukung kontemplasinya menuju Yang Suci. Sampai suatu ketika Ratu Kalinyamat Aso (dari bahasa Jawa yang berarti "istirahat") lalu Semende (dari bahasa Jawa yang berarti "bersandar"), maka kemudian daerah tersebut terkenal Sonder yang terletak di desa Tulakan Keling Jepara (Said, dkk., 2005: 82). Di Sonder inilah Ratu Kalinyamat merasa cocok dengan lingkungan dan suasana mitisnya sampai akhirnya melakukan pertapaan atau dikalangan sufi dikenal dengan khalwat.

Sebelum berkhalwat kepada Allah di Sonder tersebut Ratu Kalinyamat membersihkan diri baik secara lahir maupun batin dengan mangambil air dari sungai yang dikeramatkan di daerah tersebut untuk sesuci dan melakukan "mandi besar". Dalam mengambil air inilah Kanjeng Ratu mengucapkan semacam mantra yang berbunyi (Said, dkk., 2005: 82):

"Sakdurungi Allah Ta'ala gawe bumi pitu, Allah Ta'ala gawe langit pitu Allah nurunake Huruf Alif. Wujute Alif Nurullah ya Nur Muhamad kang ngebai jagat royo manjing ono ing jiwo rogoku Lailaha illallah Muhamadurrasulullah"

(Sebelum Allah SWT menciptakan bumi tujuh, Allah menciptakan langit tujuh, lalu menurunkan Huruf Alif. Wujudnya adalah Cahaya Allah dan Cahaya Muhammad (Utusan Allah) yang memenuhi jagad raya marasuk dalam jiwa ragaku. Tiada Tuhan selaian Allah, Nabi Muhammad utusan Allah)

Kutipan di atas menunjukkan ada rahasia yang sangat mendalam

el Harakah Vol.15 No.2 Tahun 2013 
dari huruf Alif. Huruf Alif itu kalau difathah bunyinya "A" kalau dikasrah bunyinya "I" kalau didzommah bunyinya "U" sehingga berbunyi "A, I, U" yang menjadi semacam akronim yang berartí "aku iki urip" (saya ini hidup). Karena manusia itu memiliki kehidupan, sebagai konsekuensinya akan kembali kepada yang memberi hidup (inna lillâhi wa inna ilaihi rajiûn), sesungguhnya manusia adalah milik Allah dan hanya kepadaNya akan kembali (Said, dkk., 2005: 83).

Rahasia huruf "Alif" juga pernah digunakan oleh RMP Sosrokartono, kakak RA Kartini yang dikenal memiliki kedalaman spiritual sehingga menjadi media pengobatan terhadap berbagai penyakit dengan materi tambahan air putih. Bagi Sosrokartono huruf "Alif" adalah simbol "Allah" yang untuk bisa sampai kepadaNya melalui caturmurti, yaitu bersatunya empat faal jiwa manusia yaitu: pikiran, perasaan, perkataan dan perbuatan. Maka bersatunya empat faal jiwa manusia tersebut juga disebut sebagai "kenyataan" (Jawa: kasunyatan) yang kemudiaan disimbulkan dengan huruf "Alif" berwujud garis wajar tanpa tambahan apapun (Ciptoprawiro, 1991: 13; Ali, 1966: 1-10).

Dalam dunia filsafat Barat, "kenyataan” yang meliputi bersatunya empat jiwa manusia tersebut disebut "waarheid", yang digambarkan seorang manusia berdiri tegak telanjang bulat. Maka kalau Ratu Kalinyamat dalam memohon keadilan kepada Sang Pencipta dengan cara tapa wuda sinjang rambut dalam perspektif ini juga menemukan relevansinya sebagai upaya menemukan jalan "caturmurti" untuk sampai pada "kasunyatan" yang tak lain adalah Allah, Sang Maha Adil (Ciptoprawiro, 1991: 13).

\section{Simpulan}

Dari uraian di atas dapat ditarik beberapa kesimpulan bahwa kehadiran Ratu Kalinyamat yang dikenal "De Krange Dame" (wanita yang gagah berani) dan "Rainha de Jepara senhora Poderosa e rice" (Ratu Jepara, seorang perempuan yang kaya dan mempunyai kekuasaan besar) dalam ruang sejarah kesultanan di pesisir Jawa telah menjadi counter budaya "atas realitas tradisi sosial yang patriarkhi.

Ratu Kalinyamat sebagai seorang perempuan ketika mendapatkan perlakuan yang tidak adil, ia berani melakukan protes dan mencari keadilan sebagaimana ketika saudaranya, Sunan Prawoto, dan suaminya, Sultan Hadiri, dirampas jiwanya oleh Arya Penangsang; maka beliau mencari upaya keadilan dengan melakukan pertapa yang dikenal "tapa wuda sinjang rambut".

Di masyarakat hal tersebut telah melahirkan beragam makna spiritual 
yang di dalamnya tak lepas dari sistem tanda (sign) sehingga memunculkan berbagai pesan "moral spiritual" antara lain: (1) Dari kelompok elit pemerintah memaknai memaknai "tapa wuda" sebagai kiasan yang memiliki pengertian meninggalkan segala bentuk urusan keduniaan dan melepaskan kebesaran mahkota kekuasaan sebagai Ratu untuk menemukan keheningan agar mendapatkan keadilan dari Sang Pencipta; (2) Dari kelompok masyarakat akar rumput memaknai "tapa wuda" meliputi dua arus; (a) Kalangan awam memaknai "tapa wuda" secara lugas sebagai telanjang bulat hanya berbaju rambutnya yang panjang terurai (sinjang rambut) sehingga memiliki pesan spiritualisme estetik yang kemudian dikenal dengan "susuk cairing Kanjeng Ratu”; (b) Kalangan kaum sufi memaknai Ratu Kalinyamat sebagai "bojo njero" (istri dalam/istri bayangan) untuk mendongkrak siritualitas para wali atau ahli thariqat yang kebanyakan laki-laki untuk sampai Tuhan. Dalam hal ini "tapa wuda" lebih dimaknai sebagai proses khalwat dalam keheningan untuk menemukan keadilan sejati dari Sang Maha Adil yang proses spiritualnya dikenal dengan huruf "Alif" sebagai simbol Allah. Untuk bisa sampai kepadaNya diraih melalui "caturmurti", yaitu bersatunya empat faal jiwa manusia yaitu: pikiran, perasaan, perkataan dan perbuatan. Hal ini menuntut kekosongan jiwa (telanjang) yang kemudian hanya diisi mahabbah (cinta) dan taqarrub (mendekatkan diri) kepadaNya.

\section{Daftar Pustaka}

Ali, R. Mohammad, 1966. Ilmu Kantong Bolong Ilmu Kantong Kosong. Djakarta: Bhratara.

Arbaningsih, Dri. 2005. Kartini, dari Sisi Lain, Melacak Pemikiran Kartini tentang Emansipasi Bangsa. Jakarta: Penerbit Buku KOMPAS.

Armstrong, Karen. 1993. A History of God, The 4,000 - Year Quest of Judaism, Christianity and Islam. New York: Ballantine Books.

Barthes, Roland. 1967. Elements of Semiology. London: Jonathan Cape.

Barthes, Roland. 1983. Mitologies. New York: Hill and Wang.

Ciptoprawiro, Abdullah. 1991. Alif, Pengertian Huruf Alif dalam Paguyuban Sosorokartono dalam Kandungan Al-Qur'an dalam Kejawen. Surabaya: Penerbit Paguyuban, Sosrokartono Surabaya bersama Yayasan "Djojo Boyo" Surabaya. 
Eliade, Mircea. 1996. The Reality of the Sacred. dalam Pals, Daniel L. Seven Theory of Religion [hlm. 158-197] New York: Oxford University Press.

Durkheim, Emile. 1996. Society as Sacred. Dalam Pals, Daniel L. Seven Theory of Religion [hlm. 88-123]. New York: Oxford University Press.

Durkheim, Emile. 1965. The Elementary Form of Religious Life. New York: The Free Press.

Gustami, SP. 2000. Seni Kerajinan Mebel, Ukir Jepara; Kajian Estetik Melalui Pendekatan Multi Dimensi. Kanisius. Yogyakarta.

Hayati, Chusnul; Priyanto, Supriya dan Indriyanto. 1991. Ratu Kalinyamat Sebagai Tokoh Historis Legendaris, (Semarang: Laporan Hasil Penelitian, Fak. Sastra UNDIP Semarang,)

Kleden, Ignas. 2004. "Pengantar Penulis" dalam Sastra Indonesia Dalam Enam Pertanyaan, Esai-esai Sastra dan Budaya, Jakarta: Grafiti

Masya, A. Mukarram. 1991. Sultan Hadiri dan Ratu Kalinyamat, Sebuah Sejarah Ringkas. Jepara: Tim Penyusun naskah sejarah Sultan Hadiri dan Ratu Kalinyamat dalam rangka menyambut khoul Sultan Hadiri Mantingan.

Mohamad, Goenawan. 2006. Catatan Pinggir, TEMPO. Edisi 44/XXXV/25 $-31$.

Pemda Jepara. 2004. Jepara Selayang Pandang 2004, Jepara: Pemda

Pemda Jepara. 2003. Jepara, Sejarah dan Budaya; Legenda Obyek-obyek Wisata. Jepara: Kadin Perhubungan dan Pariwisata.

Pemda Jepara, 1989. Lembaran Daerah Kabupaten Daerah Tingkat II Jepara Nomor 2 Tahun 1989 Seri D No. 1". Jepara: Pemda Jepara.

Pemda Jepara, 2003. Lembaran Daerah Kabupaten Daerah Tingkat II Jepara Nomor 2 Tahun 1989 Seri D No. 1; Peraturan Daerah Kabupaten Daerah Tingkat II Jepara Nomor 9 Tahun 1988; tentang; Penetapan Hari Jadi Kabupaten Daerah Tingkat II Jepara", Jepara: Bagian Hukum dan Organisasi Sekretariar Daerah Kabupaten Jepara.

Prasetyo, Ny. Hisom. Tt. Ratu Kalinyamat dan RA Kartini; Tanggung Jawab Moral Wanita Jepara. Jepara: PKK Kabupaten Dati II Jepara. 
Risakotta, Bernard Adenay. 2002. "Modernitas, Agama dan Budaya Nenek Moyang: Suatu Model Masyarakat Indonesia", disampaikan dalam dalam Internasional Conference of Anthropology, di Depasar; Indonesia, tanggal 17 July 2002.

Said, Nur; Ghufran, M. Nur; Roy, M.. 2005. Mitologi Ratu Kalinyamat dan Budaya Kapitalis (Kajian Semiologi Peran Mitos Ratu Kalinyamat dan Hubungan Signifikasi dengan Kemandirian Ekonomi Kaum Perempuan di Jepara Jawa Tengah). Jakarta: Laporan Penelitian Riset Unggulan Bidang Kemanusiaan dan Kemasyarakatan, LIPI.

Sunardi, St., 1992. Semiotika Negativa. Yogyakarta: Kanal. 